\title{
PROJECT RISK SCREENING MATRIX FOR STREAM MANAGEMENT AND RESTORATION
}

\author{
Colin Thorne $^{1}$, Janine Castro ${ }^{2}$, Brian Cluer $^{3}$, Peter Skidmore ${ }^{4}$, and Conor Shea ${ }^{5}$
}

1. School of Geography, University of Nottingham, Nottingham NG7 2RD, UK colin.thorne@nottingham.ac.uk Tel: 44-(0)115-9515431 Fax: 44-(0)115-9515248

2. US Fish and Wildlife Service, 2600 SE $98^{\text {th }}$ Ave., Suite 100, Portland, OR 97266

3. NOAA-NMFS, 777 Sonoma Ave., Room 325, Santa Rosa, CA 95404

4. Skidmore Restoration Consulting, LLC, 323 N Plum Avenue, Bozeman, MT 59715-3826

5. US Fish and Wildlife Service, 1655 Heindon Road, Arcata, CA 95521

\begin{abstract}
The 'Project Risk Screening Matrix' derives from a broader effort to assist US government agency staff in reviewing proposed stream management and restoration projects more efficiently and effectively. The River Restoration Analysis Tool (RiverRAT) developed through this effort provides a thorough, comprehensive and auditable approach to review and evaluation of proposed stream actions and projects (www.restorationreview.com). The matrix was initially developed as the first step in applying the RiverRAT, its purpose being to assist reviewers in assessing the risk to natural resources associated with a particular proposal and matching the intensity of their review to the severity of that risk. Hence, the primary application of the matrix to date has been to identify and screen out low risk projects that may be dealt with expeditiously, and so freeing the time and technical resources needed to allow deep reviews of higher risk projects. A second form of screening emerged from this primary function because the matrix proved adept at identifying the minimum level of site and project characterization required to support initial risk assessment. On this basis, proposals lacking adequate information can also be screened out, being referred back to the proponent with a request for additional information. More recently, new and novel versions of the matrix, featuring modification and refinement of one or both of the original axes, have emerged to widen and refine its application to linear infrastructure (e.g. pipelines, roads, and electrical transmission lines), instream structures (e.g. large wood placement and culvert removal), and pre-application, regulatory, decision-support tools.
\end{abstract}

KEYWORDS: Permitting, Project Review, Impact Assessment, Restoration, River Management, Risk Analysis, RiverRAT, Stream Response 


\section{Background}

In 2008, the authors developed the River Restoration Analysis Tool (RiverRAT) to provide government regulators and project reviewers (herein referred to as reviewers) with a thorough and comprehensive approach to review and evaluate proposed river management and restoration actions and projects (Skidmore et al., 2009, 2011, 2012; Cluer et al., 2010). During beta-testing of the prototype RiverRAT it became apparent that the effort reviewers could expend in applying the approach was in practice severely limited by the large number of proposals to be reviewed, coupled with statutory limits on the time allowed between receipt of a proposal and communication of a permitting decision to its proponent. For example, under the Endangered Species Act (ESA) of 1973 (Public Law 93-205, as amended; Department of Interior, 1973), the NOAA National Marine Fisheries Service and the US Fish and Wildlife Service (the Services) have up to 135 days to complete a formal consultation, while the US Army Corps of Engineers has 120 days to issue an individual permit under the Clean Water Act of 1977 (US Senate, 2002), which includes 30 days for public comment (Public Law 95-217, as amended).

It also emerged that while application of the RiverRAT approach was both justified and sufficient for many proposed projects, it represented procedural overkill for some of the lower risk projects, while additional technical reviews requiring hydrological, hydraulic, sediment and/or morphological expertise were required for a smaller number of high risk proposals. For example, when evaluating risk to aquatic species, a project involving channel reconstruction and lowering of the floodplain (Figure 1) requires more thorough scrutiny than one to place large wood in a bedrock controlled stream (Figure 2). This is because, even for restoration projects, short-term impacts during construction (such as dewatering of the stream), and longer-term impacts (such as increased fine sediment availability due to exposed soils), pose some level of risk to species, habitats, and their supporting processes. Inevitably, the deeper the scrutiny, the greater the time and effort required from the reviewer.

This poses a dilemma to reviewers: they must keep their backlog of proposals manageable, while still ensuring that high risk proposals are reviewed adequately. It follows that time and effort must not be wasted in over-scrutinising proposals that pose very little short or long-term risk to resources. Clearly, a balance must be struck through which the possibility of missing a high risk proposal is properly set against the need to move proposals through the assessment system within the time available. This requires that reviewers work efficiently, expediting reviews of projects that pose very little risk, while guarding against high risk proposal slipping through with inadequate review.

The project risk screening matrix (the matrix) described herein was, therefore, derived in the latter stages of RiverRAT development, to assist reviewers in assessing the risks to species and habitats associated with a particular proposal and, thus, helping them select the appropriate depth of scrutiny. The matrix was specifically designed to enable early career reviewers avoid being overly cautious in assessing project risks, through accelerating development and calibration of their skills in distributing review time and intensity between proposals for different types of projects undertaken in different types of streams. In practice, the matrix has 
also proven valuable to experienced reviewers because it provides for equitable treatment of proposals by assuring that risk factors are evaluated consistently, and it serves as a guide to making adjustments when necessary.

The matrix cannot, however, replace a reviewer's professional judgment. Rather, it is a yardstick that can be used in enhancing and refining that judgment, for which there is no viable alternative. The matrix may also be useful when reviewers need to communicate with applicants to explain their decisions, discuss the risks associated with a proposed project or its potential for unintended consequences, or justify a request for additional data or analysis.

While the matrix was initially developed for Services staff engaged in reviewing proposals for river restoration, it was always intended to be amenable to modification and adaptation. In fact, since its inception in 2009 (Skidmore et al. 2009) the range and variety of applications for the matrix that have emerged demonstrate both the flexibility of the tool and general applicability of the underlying concept. In this paper, the evolution of the matrix first conceived by the authors of RiverRAT is recounted, example applications to three types of project are presented, and further modifications and adaptations employed by other practitioners are discussed.

\section{Risk-Based Assessment of Restoration Proposals}

The matrix is a crucial part of a wider effort to provide structure and context for stream restoration project reviewers. The principal underpinning RiverRAT is that the risks of harm to species, either directly or as a result of modifications to their habitats and/or supporting processes, associated with restorative actions must be acceptable or at least tolerable (www.restorationreview.com). Within RiverRAT's risk-based protocol, the purpose of the matrix is to identify:

(i) project proposals that fail to provide sufficient information to support an initial riskassessment;

(ii) low risk projects that may be dealt with expeditiously, and;

(iii) high risk project proposals that require investment of additional time and effort to allow deep review including, if necessary, assessment by technical specialists in hydrology, hydraulics and/or geomorphology.

Clearly, reasonable levels of project and site characterisation are required for application of the matrix. Proposals that lack the information necessary to perform even basic risk assessment and screening must either be returned to the proponent with a request for further details or evaluated under a worst-case scenario. Without additional details, the reviewer assumes that the unknown risks are high and, hence, further data collection and analyses by the project proponent should never result in increased risk. An explicitly risk-based decision to request additional data or further analyses also allows the project proponent to re-evaluate whether 
the potential benefits associated with the project as proposed merits the investment required to properly assess its risks, or whether an alternative project option might be preferable.

Once sufficient information is available, the time and effort expended in project review should be scaled on the relative risk to resources. The matrix is used to assess the risk of doing harm within the context of the legislation under which reviewers are performing their evaluation. For example, in the case of the Services this will usually centre on the Endangered Species Act (Department of the Interior, 1973) and in this context 'resource' refers to one or more of the listed species and their habitats. However, regulatory staff with the US Army Corps of Engineers (USACE) operate under Section 404 of the Clean Water Act (US Senate, 2002) and have a different definition of 'resource'. The 'resource' in their case is, primarily, water quality in a 'Water of the United States', which is a strictly defined type of water body. Conversely, USACE regulatory staff may also be working under Section 10 of the 1899 Rivers and Harbors Act (as amended) (US Congress, 1899), in which case 'resource' would extend to the navigability of the watercourse.

There are, of course, many risks associated with river restoration projects other than those to listed species, natural resources and river functions such as navigation. For example, an engineer responsible for designing a wood placement project in a river used by recreational boaters would certainly need to ensure that the project posed no significant risk to life.

While the resource at risk varies between agencies and users, the matrix retains the form of a two-axis graph (Figure 3) in which the:

$\mathrm{x}$-axis = risk due to stream and site response potential, and;

$y$-axis = risk due to project impact potential.

Risk can be defined as the product of the probability of occurrence of a particular outcome and the consequences should that outcome actually occur (Oxford English Dictionary, 1989). In the matrix developed for the Services, risk is specific to listed species and their habitats. In this context, risks to listed species and their habitats may result directly, due to the impacts of actions associated with implementing the proposed project, or indirectly, as a result of responses to the project in the stream (fluvial) system.

In Figure 3, the x-axis represents the potential for the stream to respond morphologically to natural or anthropogenic disturbance (Knighton, 1998). This axis, therefore, uses indicative landscape, catchment (watershed), drainage system, and stream channel attributes to assist reviewers in assessing the probability of species and habitats being impacted due to the inherent sensitivity of the fluvial system to disturbance (Sear et al., 2010). Some stream types are naturally sensitive to disturbance, while others may have been sensitized due to past or present land use, engineering, and management practices (Macklin and Lewin 2003; Newson, 1994). 
In the science document that accompanies and supports RiverRAT, Skidmore et al. $(2009 ; 2011)$ argue that the sensitivity to disturbance of a stream depends on:

1. the nature and extent of fluvial system instabilities, including those addressed by the proposed action or project (Cluer and Thorne, 2013);

2. the capacity of the channel to absorb disturbance through multiple, small adjustments to hydraulic geometry that fall within the boundaries of meta-stable, dynamic equilibrium (Hey, 1978);

3. the capacity of the channel-floodplain system to store or release sediment without triggering significant morphological changes through degradation, aggradation, lateral instability or planform metamorphosis (Schumm, 1977);

4. the resilience of in-stream, riparian and floodplain vegetation to changes in the flow regime, sediment regime, fluvial processes and channel morphology (Bennett and Simon, 2004);

5. the space available for riverine ecosystems and species to adapt to environmental and morphological changes within in the channel migration zone (Rapp and Abbe, 2003).

Attributes 1 through 4 together control the probability that a given action will trigger responses in the fluvial system sufficient to impact resources directly or indirectly through destabilising the channel, while attribute 5 represents the potential for disturbance to habitat and ecosystem functions to be accommodated and/or naturally mitigated without adversely affecting listed species.

Because the $x$-axis relates to the natural and inherited attributes of the host catchment and stream, the associated risk can only be reduced if the project site is relocated or additional data collection and enhanced catchment/stream characterisation establishes that the initial assessment was overly cautious. Additionally, because morphological responses to disturbance tend to be transcendental and cyclical (Cluer and Thorne, 2013), long-term impacts are more likely in sensitive fluvial systems.

The $y$-axis is directly associated with the proposed action or project itself. Some disturbance to the fluvial system at the site, reach or system scale is inevitable when performing engineering, management or restoration actions in or near a stream (Sear et al., 2010). This axis, therefore, supports qualitative assessment of the risk to species and habitats associated with a proposed action or project on the basis of: the broader reach and catchment context within which the project will occur; descriptors of the potential for specific design elements of the project to remove or introduce artificial constraints; information on the construction method; and the presence or absence of plans for future monitoring and adaptive management.

In the science document that accompanies and supports RiverRAT, Skidmore et al. $(2009 ; 2011)$ argue that the consequences of a stream response triggered by actions and projects depend upon the: 
1. quality and extent of the data and analyses used to characterise the stream and project (FISRWG, 1998);

2. quality and scope of planning for the action or project and, particularly, whether the catchment context has been properly established (Downs and Gregory, 2004);

3. potential for implementation, operation and maintenance to adversely impacted stream, riparian, and floodplain functions, habitats, and species (Harvey and Wallerstein, 2009);

4. degree to which the action or project may impede the capability of the stream to accommodate future disturbances or prevent natural recovery (Hey, 1978);

5. plans for post-project monitoring and adaptive management to address unforeseen morphological impacts and so manage down future risks to habitats and species (Downs and Kondolf, 2002).

Attributes 1 through 4 together help to mitigate the potential consequences when the impacts of the proposed action or project are sufficiently intensive, extensive or persistent to significantly disturb or destabilise the channel and so pose a potential threat to species. Attribute 5 represents the degree to which the project proponents recognise that not all risks to resources can be foreseen and have incorporated mechanisms to first detect and then reduce hazards associated with future, adverse impacts that result from the unintended consequences of their action or project.

Because the $y$-axis relates directly to the proposed action or project, it is usually feasible to reduce or mitigate the known risks to species and habitats by redesign or use of Best Management Practices (BMPs) during implementation. Furthermore, risks stemming from the potential for unforeseeable, negative responses may be reduced through the addition of project elements providing post-project monitoring and adaptive management.

\section{Explanation of the Risk Factors}

Development of RiverRAT over several years, from the initial Science Document (Skidmore et al. 2009) to the published Technical Note in 2011 (Skidmore et al. 2011), inclusive of Beta testing by end users and application by the authors in the intervening years, resulted in changes to the matrix over time. The initial, 2009, version of the matrix was subject to substantial changes in 2011. Because several of the modified and adapted matrices reported later in this paper are based on the 2009 edition of the matrix, that version is presented here, followed by a summary of changes incorporated into the 2011 version. The authors fully expect evolution of the attributes and parameters in the matrix to continue, both within and between applications. This is inevitable because, as discussed above, decisions on the inclusion, addition or removal of attributes from each axis are made by project reviewers with different regulatory authorities regarding the protection of threatened and endangered species or specific stream functions. Hence, inclusion of particular attributes, especially on the y-axis, may be more or less relevant and meaningful depending upon the application (this is discussed further in the Section on 
modifications, below). It follows that the order in which attributes are presented may not indicate their importance while attributes may not be weighted equally for all streams or projects.

\section{$x$-axis attributes related to stream response potential}

\section{Scale of problem to be addressed}

Magnitude of stream response generally scales on the spatial extent of the problem. Hence, the risk associated with, for example, a project related to a bank erosion or bed siltation problem will result in extensive habitat change is usually lower when it is restricted to a specific site or reach compared to when instability is manifest in multiple reaches or, especially, is endemic to the fluvial system and watershed.

\section{Landscape setting}

Some streams are naturally resilient to disturbance, while others are highly sensitive. This depends largely on the landscape setting within which the stream is located and the capability of the channel-floodplain system to adapt to changes in the flow and sediment regimes without sudden morphological adjustments. Generally, the wider and better connected the floodplain, the lower the inherent sensitivity of the stream channel (Cowx and Welcomme, 1998). Incised channels and channels crossing alluvial fans are particularly sensitive and prone to destabilisation by what may appear to be relatively minor disturbances (Beechie et al., 2008).

\section{Channel type/classification}

Channel response to disturbance also varies by channel type. A stream classification system that provides a basis for evaluating the probability of morphological response, based on the balance between sediment supply and sediment transport capacity, is useful for project evaluation. In the Montgomery and Buffington (1998) classification, "Response" channels correspond to sediment transport-limited channel types, "Transport" channels correspond to sediment supply-limited channel types, and "Source" channels are dominated by local colluvial sediment inputs from hillslopes, and are often geologically controlled. Consequently, channelrelated risks intrinsic to the stream are lowest in Source (colluvial) reaches, intermediate in Transport (step-pool, cascade, bedrock) reaches, and greatest in Response (plane-bed, poolriffle, dune-riffle) reaches.

\section{Bank characteristics}

The propensity for marked morphological response to disturbance of fluvial processes (flow and sediment transport regimes) is reduced in channels with naturally erosion resistant bank materials, such as rock or strongly cohesive clay (Thorne and Osman, 1988). Similarly, densely vegetated banks resist erosion and reduce the probability for disturbances to destabilise the channel and negatively impact habitat (Bennett and Simon, 2004). Conversely, probability that a stream may destabilised is greater in channels with banks that are highly erodible. Channels with artificially revetted banks are also classed as high risk -- first because the presence of bank protection indicates that bank retreat has been a problem in the past, and second because 
fluvial forces or changes in channel morphology may cause failure of the protection, leading to rapid and unnatural rates of channel change.

\section{Riparian corridor and channel migration zone}

For fully alluvial streams, the capacity of the stream to absorb disturbances without harm to habitat and species generally increases with the width of the riparian corridor (Broadmeadow and Nisbet, 2004). Conversely, the probability that the stream may be destabilised increases when the riparian corridor is artificially narrow or discontinuous. The risk to resource is greatest in urban and levee-confined streams that lack the space (i.e. a sufficiently wide channel migration zone) necessary to respond naturally to disturbance and absorb perturbations to the fluvial system while remaining in meta-stable, dynamic equilibrium (Rapp and Abbe, 2003).

\section{y-axis attributes related to project impact potential}

\section{Planning context}

The quality and scope of project planning affects the probability that a project will adversely impact the stream, how extensive the consequences may be and how those potential consequences are evaluated and mitigated, which determines the overall level of risk to natural resources (Skidmore et al., 2011). In this regard, a project that is part of a coordinated watershed plan, supported by sound scientific, socio-economic, and engineering studies that establish the catchment context, is less risky than a stand-alone project. This is the case because the potential consequences of a project that is part of a coordinated watershed plan are fully understood prior to implementation, while that understanding is limited for stand alone projects supported only by limited technical studies that extend only to the site or reach scales.

\section{Artificial constraints}

Artificial, human-induced constraints impede the capability of the stream to accommodate future changes in the flow and sediment regimes. In this respect, projects that introduce new constraints on fluvial processes, capacity for channel adjustment, or sediment exchange between the channel and floodplain are generally riskier than projects that either remove existing constraints or leave them in place (Skidmore et al., 2011).

\section{Channel stabilization}

Channel stabilization often relies heavily on artificial constraints that may be deformable or rigid, depending on the structure's capacity to adjust through time (Skidmore et al., 2011). Examples of deformable structures include large wood or vegetated soil lifts used to increase bank stability, and constructed riffles used for grade control (Figure 4). Rigid structures include riprap used for bank stabilization, and concrete sills for grade control (Figure 5). 


\section{Construction proximity to stream}

While some disturbance to habitat and species is inevitable during construction, long-term impacts should be avoided or minimized. Short-term, direct impacts on aquatic species and their habitat are generally greatest when work occurs within the stream channel because of vegetation removal, soil disturbance, or the potential for introduction of toxic materials and/or invasive species for example (Stanley et al., 2010). However, disturbance of the stream banks and floodplain may pose a greater long-term risk, especially in sensitive stream types, which are evaluated on the $x$-axis. Disturbance recovery intervals for the channel bed may range from weeks to years, while recovery from disturbance to the floodplain may require decades as it only occurs during out-of-bank, flood events (Montgomery, 1994). Hence, the extent and severity of construction risks should not only be scaled to the size of stream and floodplain, but should also be scaled on the probability of that disturbance persisting for a long period of time.

\section{Monitoring plan}

Not all potential impacts can be foreseen and addressed during project design and implementation and any action has the potential to generate unintended consequences. Unforeseen and unintended impacts can be detected through robust monitoring at appropriate spatial and temporal scales. Consequently, projects that include such monitoring are of inherently lower risk (Downs and Gregory, 2004). However, monitoring is sufficient only to ensure that adverse trends and negative consequences are identified. To further reduce the risk associated with unintended consequences requires both post-project appraisal (Downs et al., 1997) and adaptive management (Downs and Kondolf, 2002). The type and frequency of monitoring required for early detection of a potential failure mechanism, and hence the opportunity for management intervention, will vary depending upon the project type (Niezgoda and Johnson, 2007).

\section{Changes in the 2011 Version}

Following release of the original matrix in 2009, the RiverRAT team conducted multiple workshops and training events throughout the western United States. Based on feedback provided from participants, changes were progressively made, culminating in the 2011 edition that was included in Skidmore et al. (2011) and which is reproduced here as Figure 6. While the structure and purpose of the matrix remained the same, several of the attributes present in the 2009 version were combined, removed and/or modified.

X-axis changes:

1. The attribute "Scale of Problem" was moved from the $x$-axis to the $y$-axis and relabeled "Scale of the Disturbance". The attribute's definition was changed from "site, reach, multiple reach, watershed" to a dimensionless parameter scaled on channel width.

2. "Landscape Setting" and "Channel Type/Classification" were combined into a single attribute, "Stream Sensitivity/Stream Type", which retained the same description.

3. "Channel Migration Zone" was dropped from the "Riparian Corridor" attribute. 
4. "Bank Characteristics" was changed to "Bank Erosion Potential", but the categories were unchanged.

5. "Bed Scour Potential" was added, with the categories "boulder/clay bed (low), gravel/cobble bed (moderate), and sand/silt bed (high) and the supporting text: Morphological response to disturbance is greater in channels with easily erodible bed materials such as sand. Channels with artificial grade control are also classed as more responsive because they indicate that vertical instability has been a problem in the past (Little and Murphey, 1982). In addition, grade control structures are prone to failure unless well designed and properly maintained, which may result in rapid upstream propagation of headcuts and a rapid regrade of the channel (Watson and Biedenharn, 1999). Conversely, a naturally coarse streambed (i.e. cobble to boulder sized sediment) generally has a lower probability of a channel response through incision.

6. "Dominant Hydrologic Regime" was added with the categories "spring-fed, snowmelt, rain, rain-on-snow, and thunderstorm/monsoon" and the supporting text: Flow characteristics are a function of climate and watershed hydrology and determine the frequency and degree of hydrologic disturbance, which affect the relative channel stability and potential for stream response. For example, spring-fed stream systems have low flow variability and hence are highly stable and predictable. In contrast, convective thunderstorm-driven hydrology results in streams with high flow variability and more frequent high flows, thus they are often disturbed and destabilized (Skidmore et al., 2011).

Y-axis changes:

7. "Artificial Constraints" and "Channel Stabilization" were merged into a single attribute, "Artificial Bed and/or Bank Stabilization". The categories were unchanged, however.

8. Cumulative effects were embedded into the merged attribute "Artificial Bed and/or Bank Stabilization", and are described as: many management, engineering, and restoration actions are small-scale, individual undertakings that are unique to their location and time of implementation. In such cases, risk to natural resources may also be small because the both project's direct impacts and its potential to trigger widespread channel instability are limited by scale effects. However, in streams where multiple, small-scale impacts are possible or have been already occurred, the risk of cumulative effects must be considered (Li et al., 1994). This is especially important if individual actions involve stabilization of the bed or banks at multiple locations within a stream or reach. In some cases, these types of action may be so widespread as to be considered pervasive and, in these circumstances, the risks associated with cumulative effects must be thoroughly addressed.

9. "Construction Proximity to Stream" was eliminated.

10. "Monitoring Plan" was modified to "Monitoring and Maintenance Plan", but the categories remained the same. 


\section{Using the Risk Matrix to Screen Restoration Project Proposals}

Once the attributes described above (in their original or modified form, as appropriate), have been assessed, reviewers can screen the project proposal based on the overall level of risk to resource. In doing so, reviewers may combine the risks associated with the various system and project attributes in at least three different ways, depending on their professional judgment. Specifically;

(1) the risk associated with each of the attributes may be considered to pose a critical threat of harm to the natural resource that is independent of all the other attributes. In this case, the precautionary principle suggests that the overall risk category is defined by the highest individual risk factor on each of the $x$ and $y$-axes.

(2) none of the attributes may be considered to be individually critical to the resource. In this case, the overall risk category is defined by the average of the attributes on each of the $x$ and $y$-axes.

(3) some attributes may be considered to be more important than others, though no single attribute is, in itself, critical. In this case, the overall risk category is defined by weighting the attributes on each of the $x$ and $y$-axes.

There is no 'cook book' solution to deciding how best to select the overall risk category as each project and stream presents different challenges and risks. What is required is consistent, critical thinking and transparent, evidence-based decision-making.

After the attributes described above and represented in the axes of the matrix have been assessed, the depth of review appropriate to the proposed action or project can be selected, based on the overall level of risk to resource. To support this decision, the matrix assigns proposals to one of five overall categories, depending on the combined risks associated with the stream and with the project itself. These categories are illustrated in Figure 3 and described in Table 1.

In screening out low risk projects on low risk streams for 'light touch' review, and reallocating the time saved to support deep scrutiny of high risk projects on high risk streams, responsibility for correctly balancing expediency against precaution must rest with the individual making the decision. The matrix can be helpful in making that decision understandable, explicable, and consistent, but it should not be solely relied upon for justification.

Accepting this, the authors resisted the temptation to populate the five categories of overall risk by applying their expert judgment to commonly recurring classes of projects and types of streams. To do so generically would be dangerous as the outcome could easily be misconstrued as absolving the reviewer of professional responsibility for decisions guided by the matrix. Having said this, we have encouraged Services staff to calibrate their versions of the matrix using their own examples, as they learn to recognize which types of projects pose greater or 
lesser overall risks to resources, and gain the knowledge necessary to assess how sensitivity to disturbance varies between different streams and stream types in their physiographic region.

The left side of the matrix, which categorises streams as having a low response potential, is indicative of situations where the type of project and the way it is implemented dominate the overall risk. It follows that minimizing direct impacts during construction to reduce short-term impacts is the best way to reduce the risk to resources. In terms of monitoring and appraisal, long-term impacts are unlikely because the stream has a low response potential, indicating that the focus should be on ensuring that BMPs are applied during site preparation, construction and clean up in order to avoid unacceptable, short-term impacts.

The right side of the matrix, which categorises streams as having a high stream response potential, is indicative of situations where the stream type and catchment context dominate the overall risk. In such cases, while minimization of disturbance during project implementation remains important, the focus should be on ensuring that the impacts of short-term disturbance are not amplified and transmitted through the fluvial system to generate long-term damage and on-going risks to resources. However, as the probability of stream response remains high, post project monitoring will be essential to facilitate risk management through reducing or mitigating the consequences of any delayed impacts and responses.

\section{Application to stream restoration projects}

The following three examples are used to illustrate application of the matrix. They are actual project descriptions provided in permit application packages submitted to the state of Oregon. In these examples, the reviewer was interested only in risks to aquatic species and in-stream habitat that might result from the proposed actions. Relevant state and federal regulations, such as in-water work windows and applicable conservation measures, were also in effect.

Example 1: culvert replacement. A private forest company is proposing to replace a corroded steel culvert with an open bottom arch. The existing culvert is perched $2.1 \mathrm{~m}(7 \mathrm{ft})$ above the bed of the channel at the outlet and there is currently no upstream fish passage. The project is part of a statewide fish passage improvement plan. The channel is steep, gravel-bedded, and is

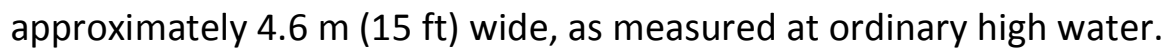

Evaluation of the $\mathrm{x}$-axis attributes results in a high risk assessment due primarily to the lack of data (Figure 7). While the channel is steep and coarse-bedded, it is not specified whether this stream is valley confined, colluvial or on an alluvial fan; however, the existence of a perch more than $2 \mathrm{~m}$ high at the culvert outfall suggests that there may be vertical instability in the fluvial system. If the perched condition of the culvert outlet is due to reach-scale channel incision, then replacing the existing structure with an open bottom arch could allow degradation to migrate upstream, potentially destabilising the fluvial system through headcutting upstream and excessive sedimentation downstream. Under this 'worst-case' scenario, the project would introduce unacceptable risks to aquatic species and habitats due to the stream's high response 
potential. While the project is part of a larger plan, the proposal does not indicate whether there will be post project monitoring at this site. Hence, the risk classification on the y-axis is moderate to high. Due to lack of sufficient information, the decision was to refer this proposal back to the originator, with a request for supplementary information based on stream reconnaissance and full details of the statewide fish passage improvement plan.

Example 2: channel construction. A private landowner is allowing stream restoration to occur on their property. The proposal is to construct $3.2 \mathrm{~km}$ ( 2 miles) of new stream channel through an existing pasture, in a wide alluvial valley within which the original meandering (pool/riffle) stream was obliterated some decades previously. The project goal is to improve aquatic habitat by restoring a meandering channel planform. Channel gradient will be stabilized using constructed riffles spaced along the channel throughout the restored reach. The existing instream habitat supports spawning, rearing, and migration for a federally-listed, threatened salmonid.

Assessment of Stream Response Potential along the $\mathrm{x}$-axis of the matrix results in a high risk categorisation because the project involves a pool/riffle stream located in a wide alluvial valley. Without any data or other evidence to the contrary, assumption of the 'worst-case' scenario indicates that post-project responses in this 'Transport' type reach might delay or prevent recovery of in-stream habitats and passage attributes lost during construction. Project Impact Potential as defined by the $y$-axis attributes is also rated as high because there is no indication of whether the project has been evaluated in a broader, watershed context or that provision has been made for post-project monitoring and adaptive management should unforeseen impacts occur (Figure 7). Furthermore, the project proposes to introduce grade-constraining structures (in the form of constructed riffles) to a channel that it is currently being utilized by a listed salmonid species. Given the high potential for local, reach and system scale impacts to both habitat and species that result in high relative risk assessments on both axes, this proposal was subjected to deep review by technical experts based upon detailed information and analyses that were required for thorough hydraulic, geomorphic and ecological evaluation of the design elements of the proposed project.

Example 3: large wood placement. A state agency is planning to place whole trees with

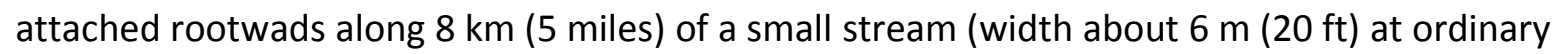
high water, using a helicopter. No artificial anchoring will be used. The channel is valley confined and incised to bedrock, with cohesive, well-vegetated banks formed in mixed alluvial and colluvial soils. The placed wood will have a minimum length of $9 \mathrm{~m}(30 \mathrm{ft})$. There are three culverts in the project reach, but they are on gated roads used only for forestry activities and regularly monitored by the state. There is no public access. The stream drains from the Coast Range directly to the Pacific Ocean. The project goal is to increase instream roughness and retain gravel to increase habitat quality and complexity with the aim of improving spawning and rearing habitat for fish, including listed salmonids. This project is identified as part of a watershed plan. Monitoring will be performed, based on annual photography from fixed points. 
Of the three examples, this proposal provides the most information relevant to assessing the risk attributes on both axes. On the x-axis, the risk to natural resources is assessed as low because the project is located in a valley-confined, bedrock controlled channel with intact riparian vegetation and naturally non-erodible colluvial banks, which is unlikely to be sensitive to disturbance. On the $y$-axis, the project is part of a broader plan, adds no additional, artificial constraints and includes post-project monitoring. The placed wood is much longer than the characteristic width of the stream, so it is unlikely to move far, but even if it is exported from the placement reach (the worst-case scenario), the potential for negative impacts to aquatic species and in-stream habitat is low and there are no risks to bridges or communities downstream, while the potential benefits are likely to be high. The decision was to subject this proposal to a light touch review (Figure 7).

While all three of these examples appear to provide a paucity of data, this is not at all uncommon for permit applications. Lack of detailed designs and specifications in the documents does not necessarily prevent permit issuance, as the purpose of review by the Services is not to determine if the standards of engineering practice have been met, but to evaluate whether the proposed actions would pose an unacceptable risk to a defined population of a listed species or its habitat.

\section{Modifications to the Matrix for Specific Applications}

\section{Overview}

While the original matrix in either of its 2009 or 2011 versions described above can be used to assess the overall risk associated with a spectrum of project types that extends well beyond what might be considered river restoration, it is less well suited to assessment of the risks associated with other specific types of project, such as stream crossings. This is because the stream and project attributes used in the original matrix do not specifically address the sources of risk associated with alternative crossing locations, design approaches, and implementation measures, resulting in limited capacity to differentiate between different hazards and clustering of risk assessments. To disaggregate risk assessments for a single project type requires refinement of the matrix, which generally involves modification of the $y$-axis to better reflect attributes specific to the type of project to be reviewed. Application of the matrix more generally requires changes to both axes. Modified risk matrices developed to date include versions for: linear projects, such as natural gas pipelines, roads, and electricity transmission lines; instream activities, such as large wood placement; and, pre-application, regulatory decision making.

\section{Pipeline Crossings}

A single linear project, such as a pipeline, road, or electrical transmission line, can cross hundreds or even thousands of streams and a risk assessment must be performed for each and every crossing. The matrix is particularly well suited for distinguishing relative risks at crossings along linear projects, and thus can serve as a decision making tool for both routing and crossing 
construction techniques. For example, during the early stages of project planning, the route of a linear project can be modified to avoid high risk crossing locations. Once the route has been finalized, the matrix can be used to assess the risks associated with alternative construction techniques in relation to the type and degree of disturbance to the channel, banks and floodplain, and response potential of the stream. For example, when crossing sensitive streams with a pipeline, lower disturbance construction techniques, such as Horizontal Directional Drilling (HDD), may be preferable to techniques, such as open trenching, that cause greater disturbance to the crossing site and have greater potential to trigger wider instability in the fluvial system. This is the case because the additional costs of HDD are fully justified by the reductions in the risks that the stream might be destabilized with adverse environmental consequences, that the pipeline might be exposed or ruptured and that further capital works may be necessary to avoid or mitigate either of these potentially catastrophic outcomes.

In the modified matrix for pipeline crossings, the $x$-axis remains essentially unchanged, while the $y$-axis introduces project attributes related to floodplain disturbance, channel disturbance, construction method, and the use of artificial bed and/or bank stabilization (Figure 8). The orientation of the pipe relative to the floodplain and channel determines the level of disturbance - the greater this deviates from perpendicular, the greater the disturbance. Similarly, the deeper the construction trench, the greater its width; hence, the intensity and extent of disturbance to the stream is increased. Use of bed and/or bank stabilization introduces further risks associated with the constraints they place on natural channel evolution and adjustment, plus the disruptive effects of on-going maintenance and potential for future failure of the structures should their design loading be exceeded.

The overall risk categories within the pipeline matrix have also been modified. Rather than indicating the level of review required, the categories specify the preferred design approach, Best Management Practices (BMPs), and monitoring requirements. For low risk streams and crossings, a prescriptive design with standard BMPs that are the same for all crossings in this category are appropriate. Because stream response potential is low, only subsample monitoring is required, and stratifying this by stream type is unnecessary. For moderate levels of overall risk, standard designs should be developed for each category of crossing type and/or stream. This may, for example, include construction practices that involve rock fracturing or crossings on step-pool streams. It follows that the standard BMPs used for lower risk projects will be increasingly tailored to specific crossing and stream attributes, as risk increases. Similarly, monitoring becomes increasingly intensive and detailed as stream response potential grows. The highest risk projects require individual designs, individual BMPs, and site-specific monitoring.

The inherent value of the pipeline matrix is that it encourages project proponents first to avoid high risk streams and crossing sites if this is possible, and then guides them on how to minimise crossing-related risks through appropriate decision making with respect to crossing design, implementation, and monitoring. The matrix also assists reviewers in allocating additional time and resources to high risk crossings to ensure that they are thoroughly reviewed, as discussed 
previously. To date, the pipeline risk screening matrix has been applied to thousands of stream crossings in the western United States (Castro, 2010; Castro et al., in review).

\section{Large Wood Placement}

Large wood is often placed in stream channels to increase flow resistance and thus habitat complexity as part of restoration, rehabilitation, or enhancement of the aquatic and riparian environment (Pess et al., 2012). While risks to listed species and their habitats associated with wood placement are usually low, other risks may be significant and the matrix has been modified to assess risks to, for example, downstream infrastructure, such as bridges. To facilitate this application, the $y$-axis is modified to account specifically for project attributes that affect wood mobility (length relative to channel width, properties, anchoring techniques), and the presence of infrastructure downstream, while stream attributes on the $x$-axis remain unchanged (Figure 9).

The additional wood-specific project attributes focus on mobility and techniques employed to hold wood in place. The length of the pieces of wood relative to channel width and the presence of a root wad are the primary controls on their mobility (Fox and Bolton, 2007). As this ratio decreases, relative wood mobility increases, and thus it becomes more likely that wood will be entrained by the flow. Through time, low density wood decays more rapidly into smaller, easily transportable pieces than dense wood. As wood becomes less stable (as a function of its original size and decay rate), reliance on artificial anchoring to keep it in place generally increases. In this context, the technique selected for anchoring is a risk factor as well as the type of infrastructure in the channel downstream of the wood placement project. It follows that, in terms of risk to infrastructure, the worst-case scenario may be for a number of cabled logs to be entrained, transported downstream as a log raft, and then trapped against a bridge pier.

The advantage of the large wood placement matrix is that it identifies combinations of project attributes and stream contexts that may result in unacceptable risks to infrastructure. It also highlights how selection of inappropriate methods of anchoring to reduce wood mobility may increase, rather than decrease, these risks.

\section{Regulatory Decision Making}

Modifications to the $y$-axis for pipeline crossings and large wood placement illustrate that the utility of the approach is not restricted to any particular project type. A more extensive reconceptualization performed jointly by the State of Oregon and the US Army Corps of Engineers involved changes to both the $x$ and $y$-axes. The intent was to develop a screening matrix for pre-consultation for permit applicants and demonstrates its viability as a tool for qualitative risk assessment in relation to almost any proposed, stream-related activity (Figure 10). 
The Pre-Application Screening Matrix (Pre-App Matrix) was developed for potential permit applicants to evaluate whether a pre-application meeting with relevant federal and state agencies representatives would be useful (USACOE, 2013). The principle underlying the Pre-App Matrix is that stream or wetland projects that are broad, complex, controversial, or have significant impacts, need and benefit from the early involvement of state and federal agencies. The common goal of the agencies is to ensure that: (i) projects do no lasting harm to on-site, upstream, or downstream aquatic habitats; (ii) short and long-term negative impacts are avoided (if possible), or minimized to the greatest extent (when and where they cannot be avoided); and (iii) that any negative impacts that remain are properly mitigated.

Pre-application meetings occur prior to submission of a complete application to the U.S. Army Corps of Engineers to elicit early feedback, identify potential hurdles and, where appropriate, facilitate alterations to design and implementation before planning has advanced to the stage that making changes has become onerous and expensive. In some cases, pre-application meetings benefit from broad participation by a range of agencies, while in others focused discussion with one or a few agencies is more appropriate. A strength of the Pre-App Matrix is its flexibility: while it is primarily intended for major projects that are large in scale or highly controversial, it is available to any potential applicant or agency, and can easily be tailored to assess the risks associated with projects that are smaller, less complex or less controversial (USACOE, 2013).

Compared to the matrices discussed earlier, the Pre-App Matrix retains only the Stream Sensitivity/Stream Type factor on its $\mathrm{x}$-axis. The other factors are all related to regulatory authorities of the state and federal agencies. The strength of this screening tool is that it provides a clear indication of which components of a proposed project may trigger the need for deep, technical review or require an additional permit from regulatory agencies, allowing project proponents to make decisions on the best way forward in developing their project that are accurately informed by the project's regulatory context.

\section{Summary and Conclusions}

The project risk screening matrix developed as part of the River Restoration Analysis Tool (RiverRAT) has proven to be a simple but useful way of screening the very large number of proposals that must be quickly evaluated to match the level of review to the risk to resources associated with the proposed project and the host stream. Subsequent modifications to the original version, undertaken spontaneously by diverse groups of end users and stakeholders, have adapted it for a range of specific applications, demonstrating its versatility and utility for rapid assessment of risks associated with practically any proposed stream restoration, management, or engineering action or project.

Beyond this, the exercise of identifying, characterizing, and weighting the stream and project attributes to be included in the matrix provides an effective forum for discussion of project- 
related risks that leads stakeholders towards a shared understanding of what is at risk, how serious project and stream-related risks are, and how they can be avoided, minimized, and mitigated. Further, the format of the matrix requires a parsimonious approach to specification of the number and characteristics of stream and project attributes; a discipline that fosters further dialogue between matrix developers and end users and which encourages adoption of a consistently risk-based approach throughout the review process.

Finally, the value of the matrix as a communication and negotiation tool should be recognised. Perhaps counter-intuitively, the matrix is actually working well when the risk assessments produced by different individuals and agencies are inconsistent. This is the case because inconsistent assessments not only elucidate differences of opinion concerning the risks associated with particular project attributes, sensitivities and tolerances, but also tease out underlying beliefs and unspoken assumptions concerning projects and stream types in a way that allows stakeholders to get at the root of a disagreement. What is unusual, and perhaps unique, about the matrix is that the discussion space it provides can embrace multiple, varying types of risk, ranging from risks to species and habitats, to risks to infrastructure and human safety.

\section{Acknowledgements}

RiverRAT was developed through a joint effort by NOAA National Marine Fisheries Service and the US Fish and Wildlife Service, with valuable inputs, beta-testing and end-user feedback from numerous state and federal agencies, academic researchers, and restoration industry professionals. We extend special thanks to the RiverRAT peer reviewers including Bill Dietrich, Pete Downs, Greg Koonce, Doug Shields, and Matt Kondolf, and to Spencer Hovekamp for initiating, steering and supporting the project throughout, and for the helpful comments from two anonymous reviewers.

The findings and conclusions in this article are, however, those of the authors and do not necessarily represent the views of the US Fish and Wildlife Service or NOAA National Marine Fisheries Service.

\section{References}

Beechie, TJ, Pollock, MM, and Baker, S. 2008. Channel incision, evolution and potential recovery in the Walla Walla and Tucannon River basins, northwestern USA, Earth Surf. Process. Landforms 33, 784-800.

Bennett, SJ and Simon, A. 2004. Riparian vegetation and fluvial geomorphology, American Geophysical Union, USA, 282p.

Broadmeadow, S and Nisbet, TR. 2004. The effects of riparian forest management on the freshwater environment: a literature review of best management practice. Hydrology and Earth System Sciences 8(3), 286-305. 
Castro, JM. 2010. Pipelines \& Stream Crossings: a new tool for determining relative risk. Presented at: Department of the Interior, Conference on the Environment, April $26^{\text {th }}-30^{\text {th }}$, 2010, Portland, Oregon.

Castro, JM. 2011. Should I be concerned? Screening projects using RiverRAT. Presented at: Salmon Recovery Funding Board, Salmon Recovery Conference, April $26^{\text {th }}-27^{\text {th }}, 2011$, Grand Mound, Washington.

Castro, JM, MacDonald, M, Lynch, E, and Thorne, CR. 2015. Pipelines and stream crossings: a risk-based approach to reduce aquatic habitat impacts. River Research and Applications. http://onlinelibrary.wiley.com/doi/10.1002/rra.2770/abstract;jsessionid=3F8976034F08580AB CA2663AB69F42C6.f01t03?deniedAccessCustomisedMessage=\&userIsAuthenticated $=$ false

City of Portland. 2001. Johnson Creek Restoration Plan. Bureau of Environmental Services, 1120 SW Fifth Ave., Portland, Oregon 97204, USA, 257p. Available at: http://www.portlandoregon.gov/bes/article/214367

Cluer, B and Thorne, CR. 2013. A Stream Evolution Model Integrating Habitat and Ecosystem Benefits. River Science and Applications, DOI: 10.1002/rra.2631.

Cluer, B, Thorne, CR, Castro, JM, Pess, G, Beechie, T, Shea, C and Skidmore, P. 2010. Tools and Science Base for Evaluating Stream Engineering, Management, and Restoration Proposals, Proceedings of the Federal Interagency Sediment Conference 2010, Las Vegas, Nevada (June 2010).

Cowx, IG and Welcomme, RL (eds). 1998. Rehabilitation of Rivers for Fish. Oxford: Fishing News Books.

Department of the Interior. 1973. Endangered Species Act of 1973 as Amended through the 108th Congress. Department of the Interior, U.S. Fish and Wildlife Service, Washington, D.C. 20240, 44p. Available at: http://www.nmfs.noaa.gov/pr/pdfs/laws/esa.pdf

Downs, PW and Gregory, KJ. 2004. River channel management: towards sustainable catchment hydrosystems. Arnold, Hodder Headline Group.

Downs, PW and Kondolf, GM. 2002. Post-project appraisals in adaptive management of river channel restoration. Environmental Management, 29(4), 477-496.

Downs, PW, Skinner, K S and Brookes, A. 1997. Developing geomorphic post project appraisals for environmentally-aligned river channel management. In, Environmental and Coastal Hydraulics: Protecting the Aquatic Habitat, ASCE, New York, 430-435.

Federal Interagency Stream Restoration Working Group (FISRWG). 1998. Stream Corridor Restoration: Principles, Processes, and Practices, GPO Item No. 0120-A; SuDocs No. A 57.6/2:EN 3/PT.653. ISBN-0-934213-59-3. Available at: http://www.nrcs.usda.gov/wps/portal/nrcs/detailfull/national/water/?\&cid=stelprdb1043244 
Fox, $\mathrm{M}$ and Bolton, S. 2007. A regional and geomorphic reference for quantities and volumes of instream wood in unmanaged forested basins of Washington State. North American Journal of Fisheries Management, 27:342-359.

Harvey, GL and Wallerstein, NP. 2009. Exploring the interactions between flood defence maintenance works and river habitats: the use of River Habitat Survey data. Aquatic Conservation: Marine and Freshwater Ecosystems, 19(6), 689-702.

Hey, RD. 1978. Determinate hydraulic geometry of river channels. Journal of the Hydraulics Division, ASCE, 104(6), 869-885.

Knighton, D. 1998. Fluvial Forms and Processes: A new Perspective, Arnold, London, 383p.

Li, HW, Lamberti, GA, Pearsons, TN, Tait, CK, Li, JL and Buckhouse, JC. 1994. Cumulative effects of riparian disturbances along high desert trout streams of the John Day Basin, Oregon.

Transactions of the American Fisheries Society, 123(4), 627-640.

Little, WC and Murphey, JB. 1982. Model study of low drop grade control structures. Journal of the Hydraulics Division, ASCE, 108(10), 1132-1146.

Macklin, MG and Lewin, J. 2003. River sediments, great floods and centennial-scale Holocene climate change. Journal of Quaternary Science, 18(2), 101-105.

Montgomery, DR. 1994. What does channel stability mean? Proceedings of the International Workshop on Ecology and Management of Aquatic-Terrestrial Ecotones, February 14-19, 1994, University of Washington, Seattle, USA, Center for Streamside Studies, University of Washington, Seattle, p. 37-41.

Montgomery, DR and Buffington, JM. 1998. Channel processes, classification, and response. River ecology and management, 112, 1250-1263.

Newson, MD. 1994. Hydrology and the river environment. Clarendon Press, Oxford, UK.

Niezgoda, SL and Johnson, PA. 2007. Case study in cost-based risk assessment for selecting a stream restoration design method for a channel relocation project. Journal of Hydraulic Engineering, Vol. 133, No. 5, 468-481.

The Oxford English Dictionary. 1989. Vol. 2. Oxford: Clarendon Press.

Pess, GR, Liermann, MC, McHenry, L, Peters, RJ and Bennett, TR. 2012. Juvenile salmon response to the placement of engineered log jams (ELJ) in the Elwha River, Washington State, USA. River Res. Applic. 28: 872-881.

Rapp, CF and Abbe, T. 2003. A Framework for Delineating Channel Migration Zones.

Washington State Department of Ecology Final Draft Publication \#03-06-027. Available at: http://www.ecy.wa.gov/biblio/0306027.html.

Schumm, SA. 1977. The Fluvial System, Wiley, New York. 
Sear, DA, Newson, MD and Thorne, CR. 2010. Guidebook of Applied Fluvial Geomorphology, Thomas Telford, London, UK, ISBN 978-0-7277-3484-6, 257p.

Skidmore, PB, Thorne, CR, Cluer, BL, Pess, GR, Beechie, TJ, Castro, JM, and Shea, CC. 2009. Science Base and Tools for Evaluating Stream Engineering, Management and Restoration Proposals, Agency Report Prepared for: NOAA Fisheries and U.S. Fish and Wildlife Service, USA $170 p$.

Skidmore, PB, Thorne, CR, Cluer, BL, Pess, GR, Castro, JM, Beechie, TJ and Shea, CC. 2011. Science Base and Tools for Evaluating Stream Engineering, Management and Restoration Proposals, NOAA Technical Memorandum NMFS-NWFSC-112, National Technical Information Service, 5285 Port Royal Road, Springfield, VA 22161, USA, 253p. Available via http://www.nwfsc.noaa.gov

Skidmore, PB, Beechie, TJ, Pess, GR, Castro, JM, Cluer, BL, Thorne, CR, Shea, CC and Chen, R. 2012. Developing, Designing, and Implementing Restoration Projects. In: Roni, P and Beechie, TJ, eds., Stream and Watershed Restoration: A Guide to Restoring Riverine Processes and Habitats. Wiley. 215-253.

Stanley, EH, Powers, SM, and Lottig, NR. 2010. The evolving legacy of disturbance in stream ecology: concepts, contributions, and coming challenges. J. N. Am. Benthol. Soc., 2010, 29(1):67-83.

Thorne, CR and Osman, AM. 1988. Riverbank stability analysis. II: Applications. Journal of Hydraulic Engineering, 114(2), 151-172.

US Army Corps of Engineers and Oregon Department of State Lands (USACOE). 2013. Joint Public Notice for monthly federal-state interagency coordination and pre-application meetings. Issue Date: January 2, 2013. http://www.oregon.gov/dsl/PERMITS/docs/404_401_RemovalFill_PreAppPacket.pdf

US Congress 1899. Act of March 3, 1899 [As Amended Through P.L. 106-580, Dec. 29, 2000] (Commonly known as the "Rivers And Harbors Appropriation Act of 1899") (Sections 9-20), 10p. Available at: http://www.epw.senate.gov/rivers.pdf

US Senate 2002. Federal Water Pollution Control Act [As Amended Through P.L. 107-303, November 27, 2002], Washington DC, 234p. Available at: http://cfpub.epa.gov/npdes/cwa.cfm?program id=45

Watson, CC and Biedenharn, DS. 1999. Design and effectiveness of grade control structures in incised river channels of north Mississippi, USA, in, Incised River Channels. Wiley, Chichester, UK, 395-422. 


\section{Table}

Table 1. Scaling the depth of review to the overall risk to resources.

\begin{tabular}{|c|c|c|}
\hline $\begin{array}{l}\text { Project Impact and } \\
\text { Stream Response } \\
\text { Potential }\end{array}$ & $\begin{array}{l}\text { Overall } \\
\text { Risk to } \\
\text { Resources }\end{array}$ & Indicated Depth and Focus of Review \\
\hline $\begin{array}{l}\text { Low Risk Project } \\
\text { Low Risk Stream }\end{array}$ & Low & $\begin{array}{l}\text { As both sources of risk associated with this action or project are } \\
\text { low, overall risk is low and a light touch review may be } \\
\text { appropriate. }\end{array}$ \\
\hline $\begin{array}{l}\text { High Risk Project } \\
\text { Low Risk Stream }\end{array}$ & Medium & $\begin{array}{l}\text { As the action or project carries a high risk to resources the } \\
\text { proposal merits full RiverRAT review, paying particular attention } \\
\text { to: the adequacy of project development (including the setting of } \\
\text { clear goals and objectives); technical strength of design } \\
\text { approaches; inclusion of a detailed implementation plan that } \\
\text { includes project-specific Best Management Practices, and; } \\
\text { evidence of prior success with similar projects. }\end{array}$ \\
\hline $\begin{array}{l}\text { Medium Risk Project } \\
\text { Medium Risk Stream }\end{array}$ & Medium & $\begin{array}{l}\text { Risks arise equally from the project and the stream in which it is } \\
\text { to be implemented, thus a full review, involving careful } \\
\text { application of RiverRAT, is warranted. }\end{array}$ \\
\hline $\begin{array}{l}\text { High Risk Stream } \\
\text { Low Risk Project }\end{array}$ & Medium & $\begin{array}{l}\text { A low risk project may still pose significant risk to resources when } \\
\text { implemented in a stream that is highly sensitive to disturbance. } \\
\text { Hence, a full RiverRAT review is merited, emphasising: adequacy } \\
\text { of watershed and stream investigations; technical design criteria, } \\
\text { and; plans for post-project monitoring and adaptive management } \\
\text { to deal with unforeseen impacts, delayed morphological } \\
\text { responses, and long-term channel changes. }\end{array}$ \\
\hline $\begin{array}{l}\text { High Risk Project } \\
\text { High Risk Stream }\end{array}$ & High & $\begin{array}{l}\text { Proposals that have a high overall risk to resource merit a deep } \\
\text { review using RiverRAT. Proposals in this category are often } \\
\text { complicated or ground breaking and the hydrologic, hydraulic, } \\
\text { geomorphological, engineering or socio-economic aspects of the } \\
\text { proposal may be sufficiently complex or challenging as to require } \\
\text { back-up from technical specialists. }\end{array}$ \\
\hline
\end{tabular}




\section{Figures}

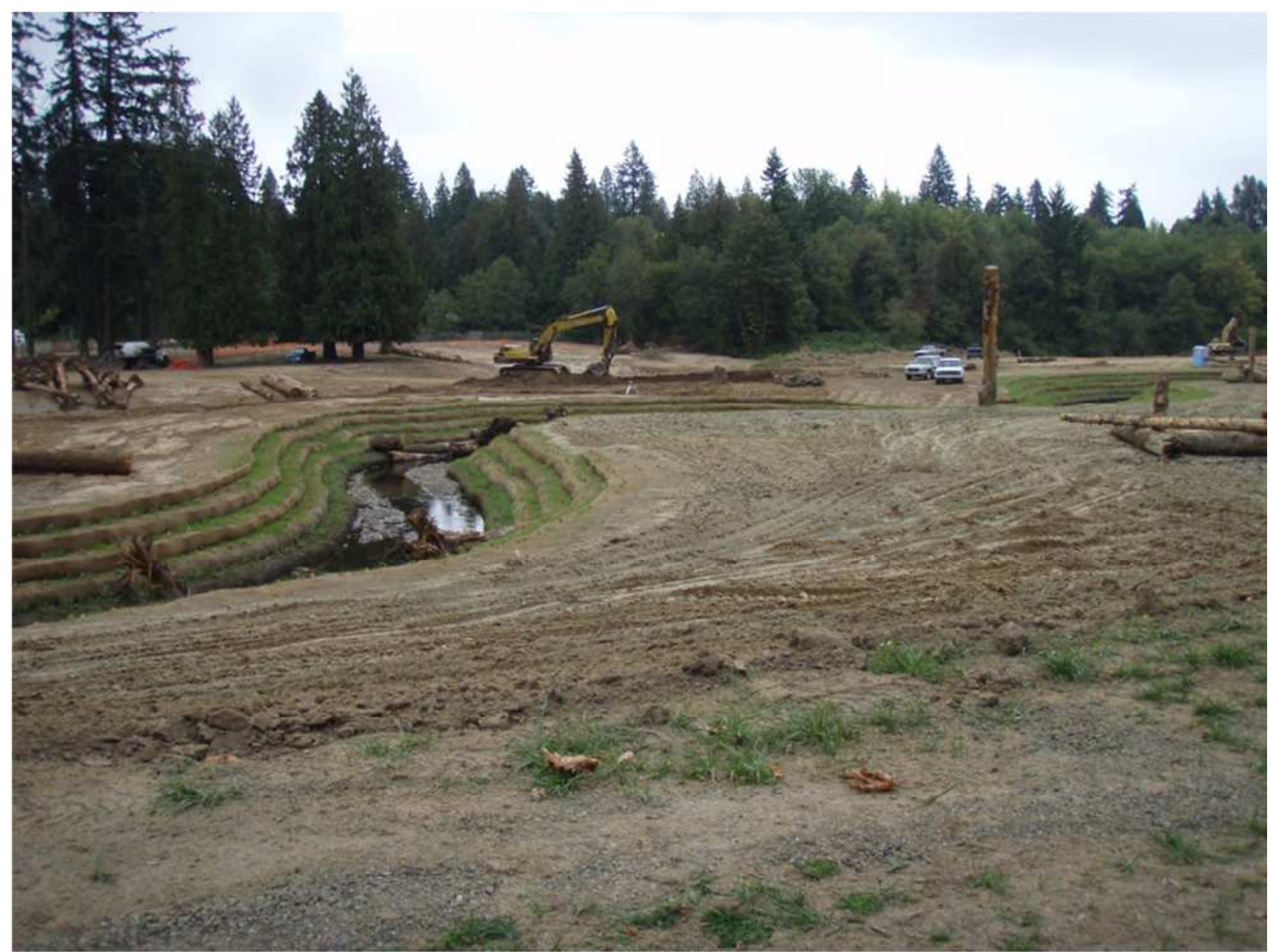

Figure 1. Due to its complexity and scale, the proposal for channel and floodplain reconstruction on Johnson Creek, Portland, Oregon (City of Portland, 2001) required a deeper technical review than that normally performed in RiverRAT. 


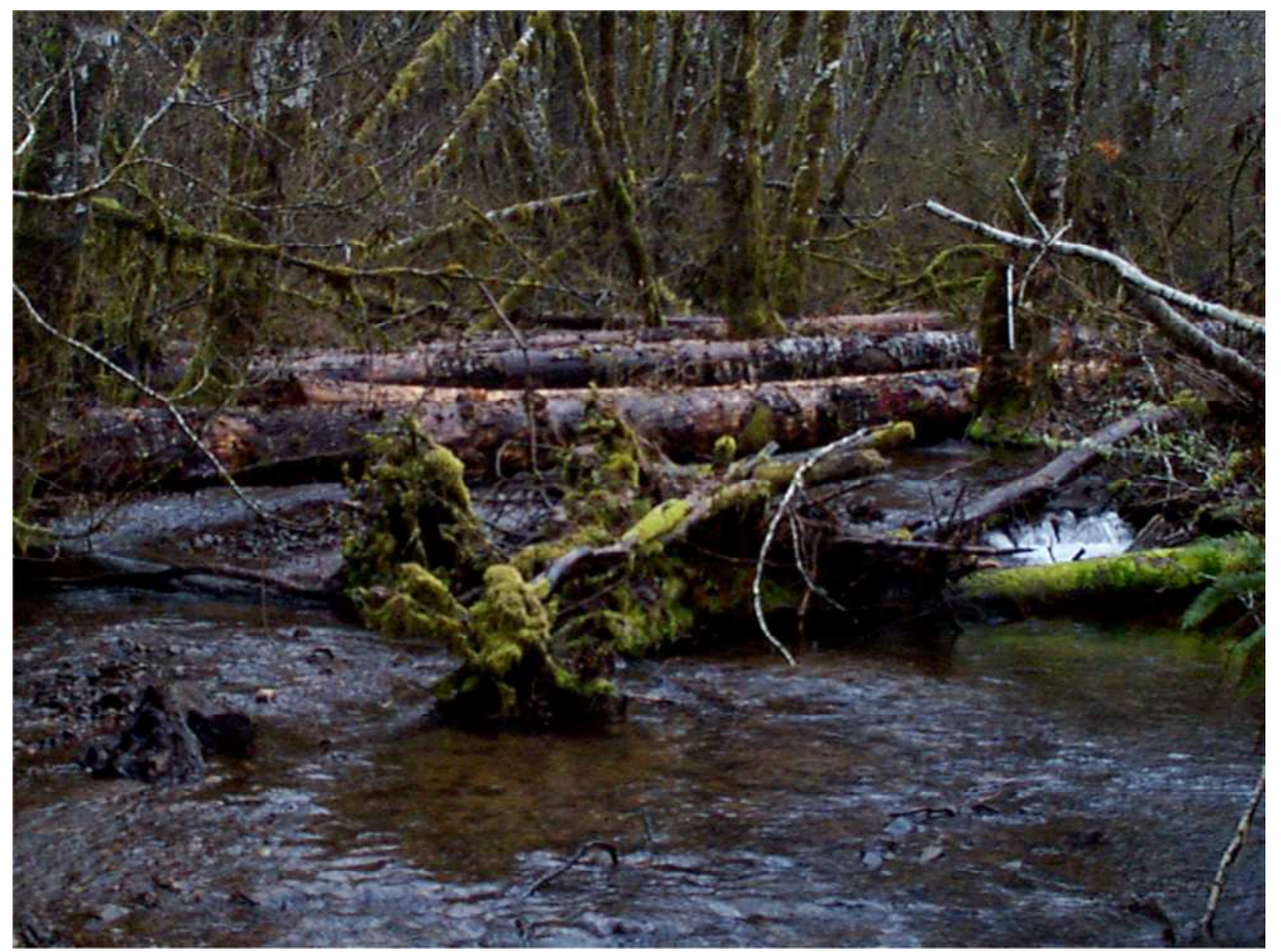

Figure 2. Large wood placement in a bedrock controlled channel, Coast Range, Oregon carried low risks to resources, infrastructure and people, and so required only a light touch review. 


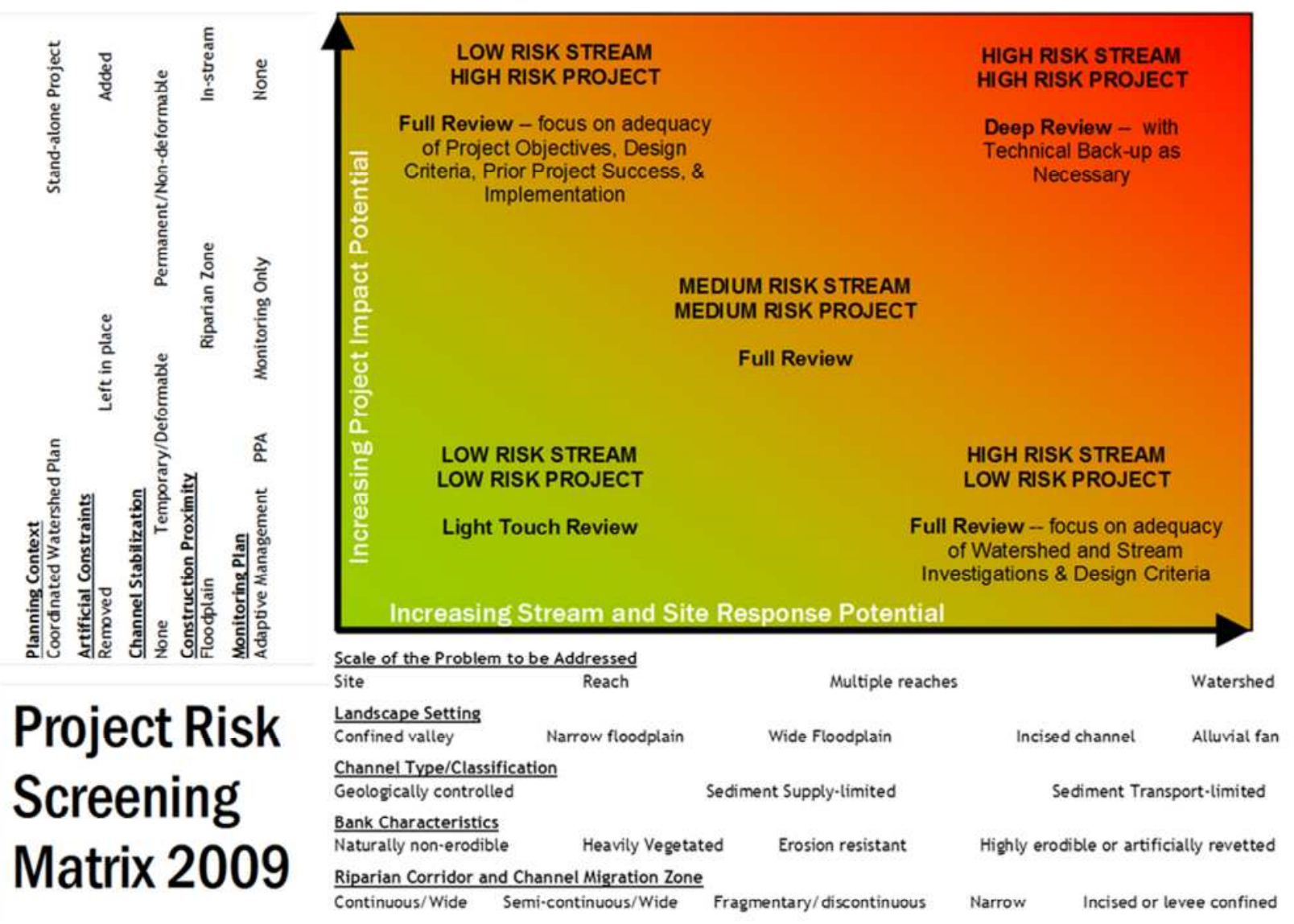

Figure 3. Original project risk screening matrix developed to assist Services staff in matching time and effort spent in reviewing a proposal to overall risk to species (from Skidmore et al.

(2009)). 


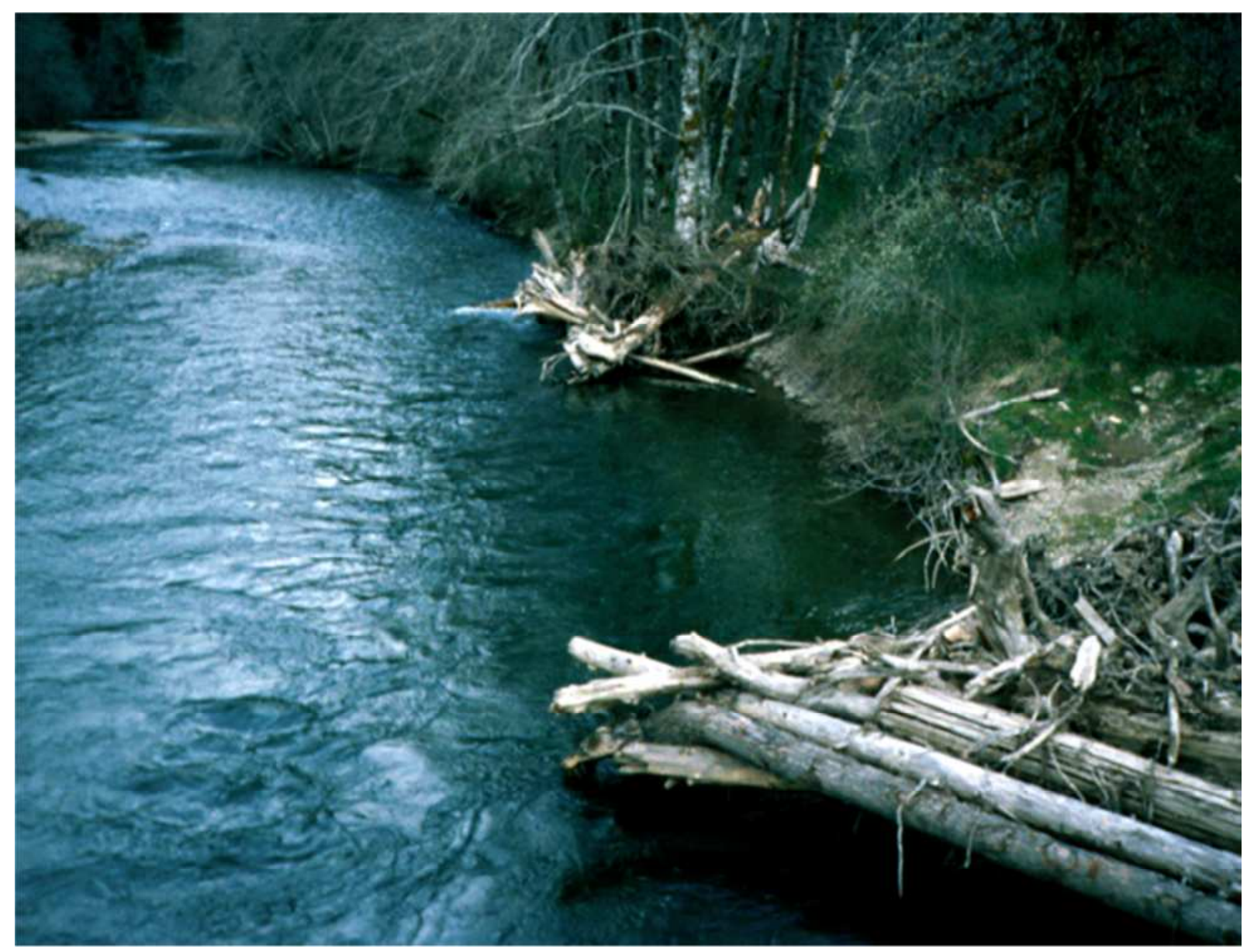

Figure 4. Large wood provides deformable bank protection that allows the channel to absorb the effects of short-term disturbances in the fluvial system and accommodate the long-term impacts of climate or land use change. 


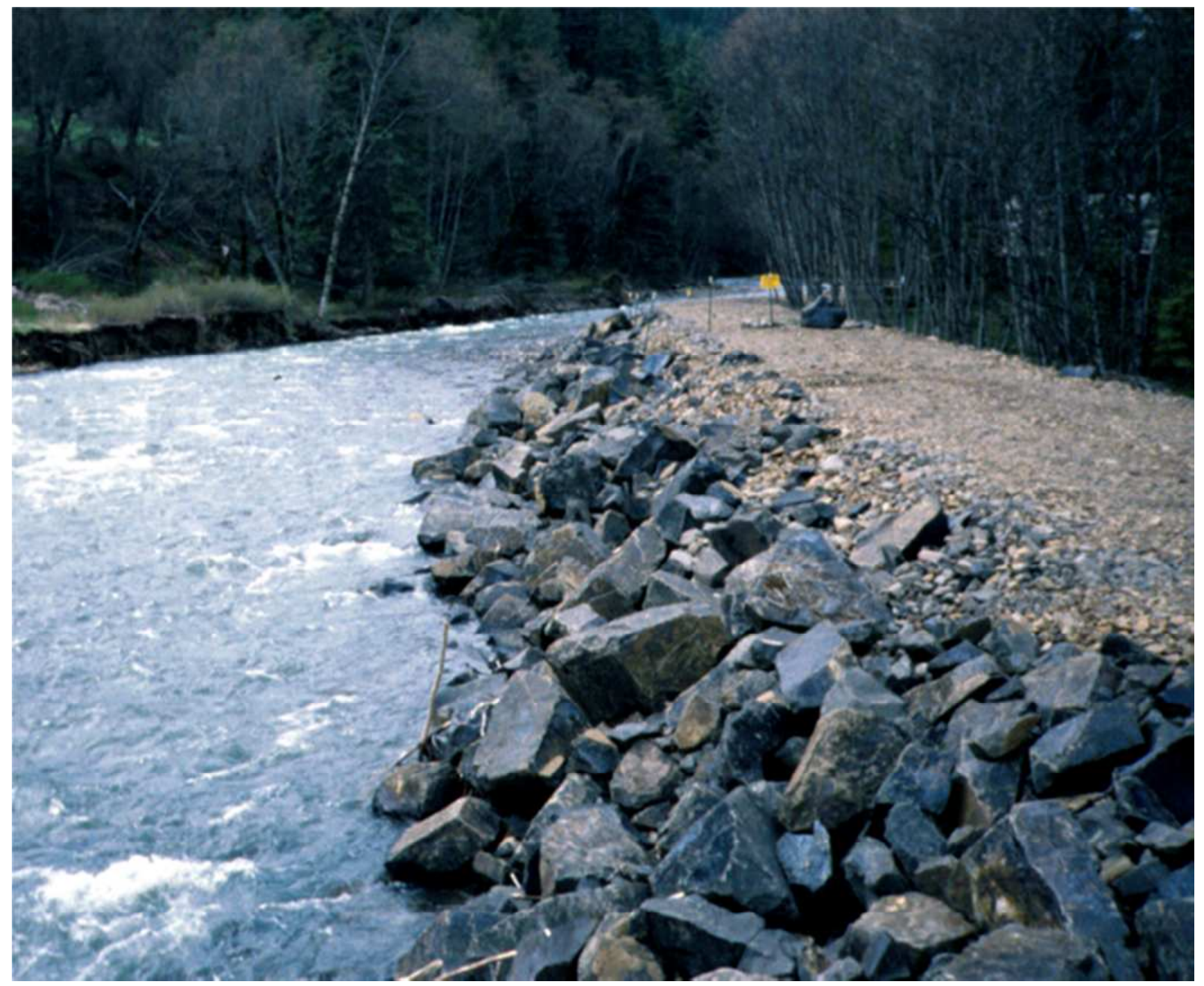

Figure 5. Riprap provides rigid bank protection that reduces the capacity of the channel to absorb the effects of short-term disturbances in the fluvial system and accommodate the impacts of long-term evolution. 


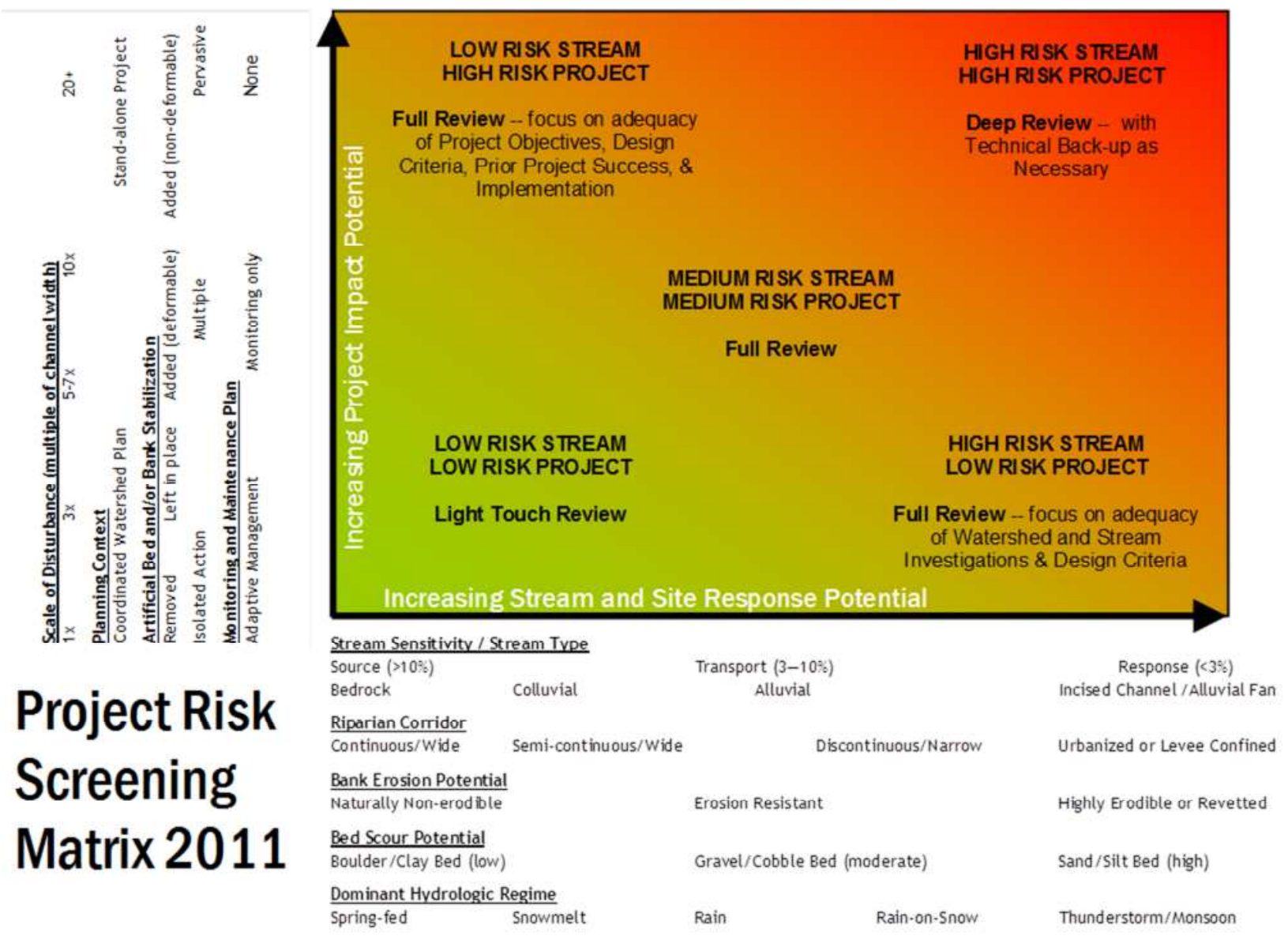

Figure 6. Updated project risk screening matrix (from Skidmore et al. (2011)). 


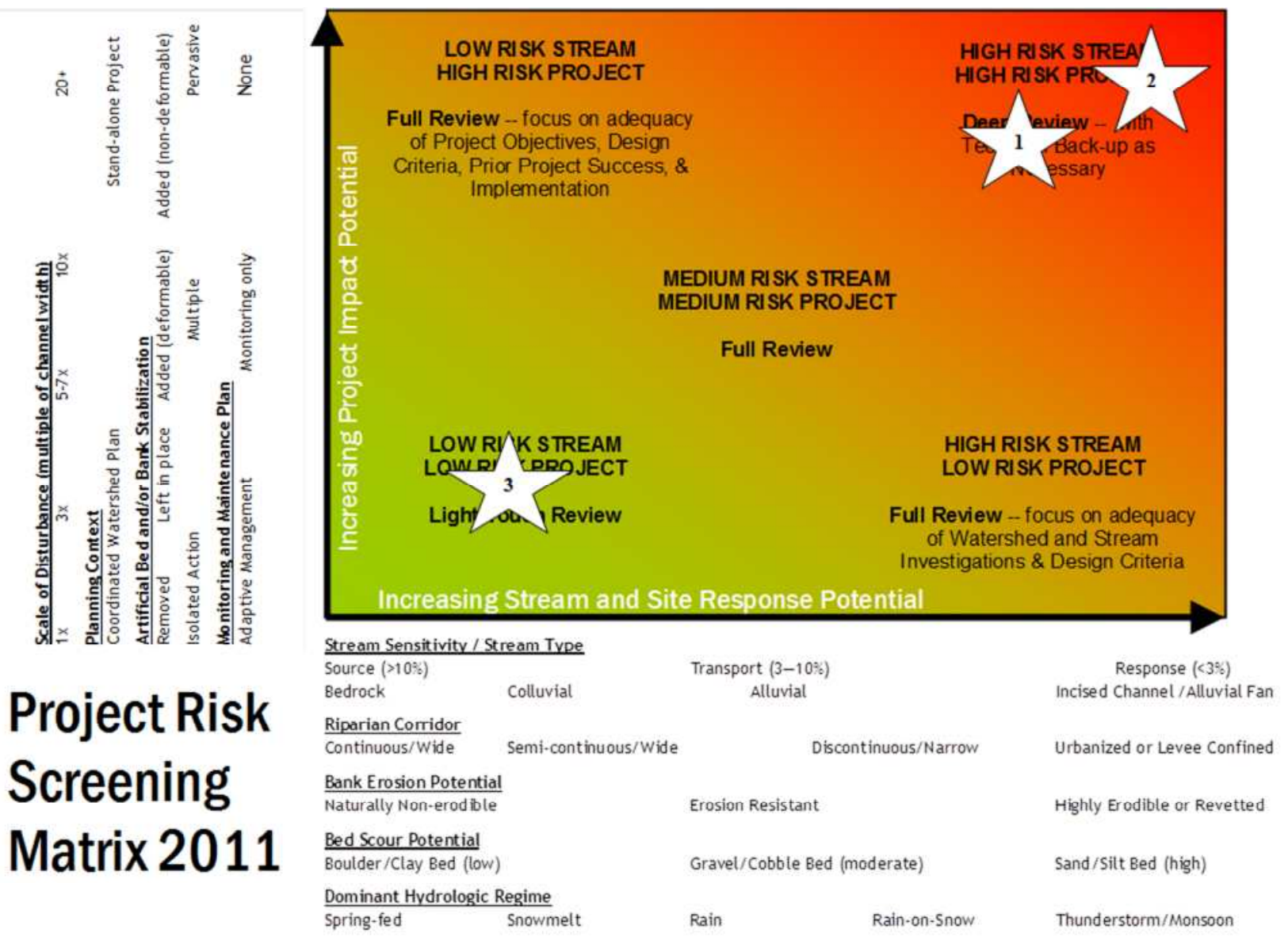

Figure 7. 2011 matrix with three example proposals for restoration projects plotted in their appropriate review categories based on evaluation of risks to aquatic species and instream habitat: 1 . culvert replacement; 2 . channel construction; 3 . large wood placement. 


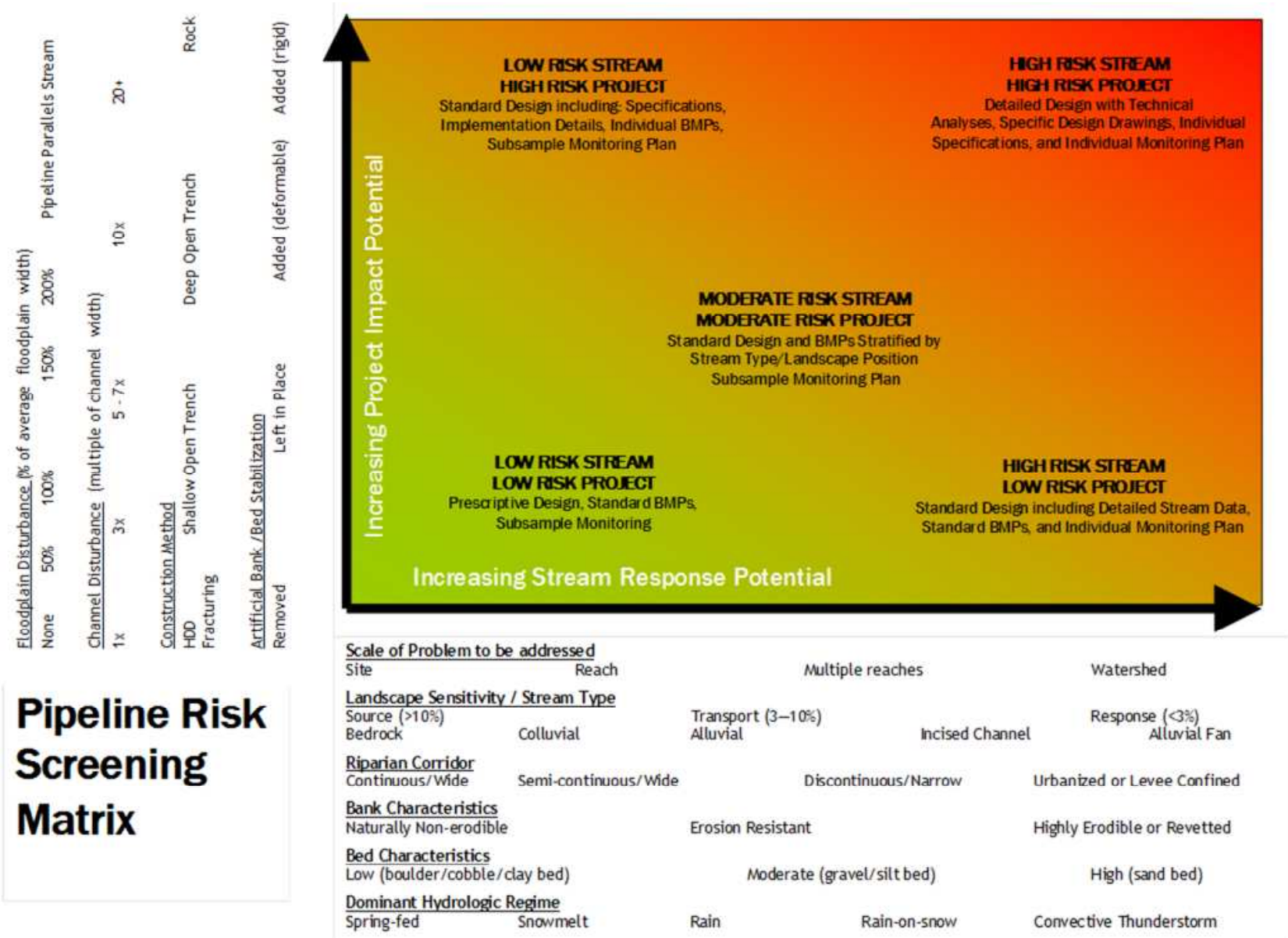

Figure 8. Pipeline crossing risk screening matrix (modified from Castro (2010) and Castro et al. (2015)). 


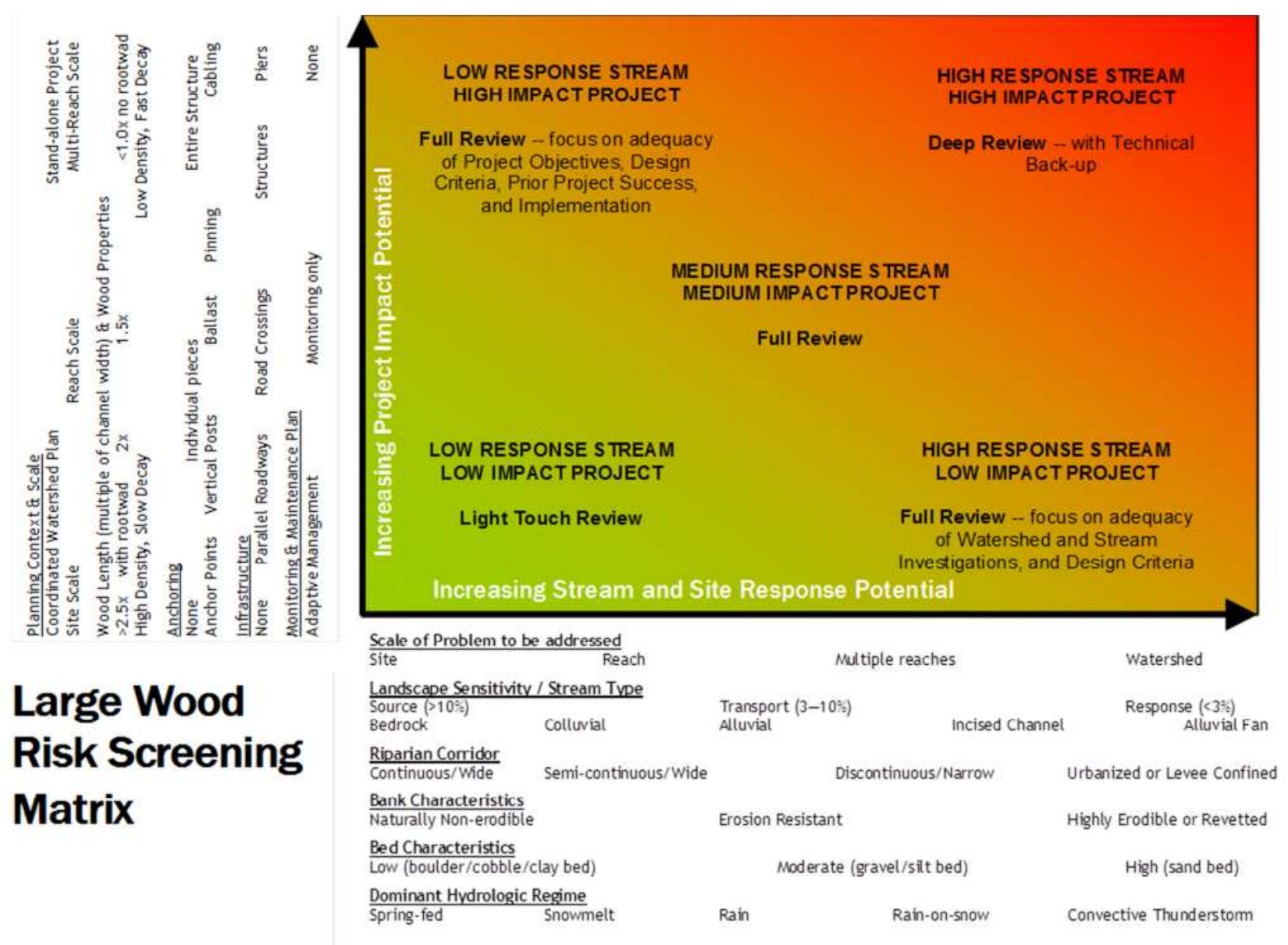

Figure 9. Risk screening matrix for large wood placement projects (Castro, 2011). 


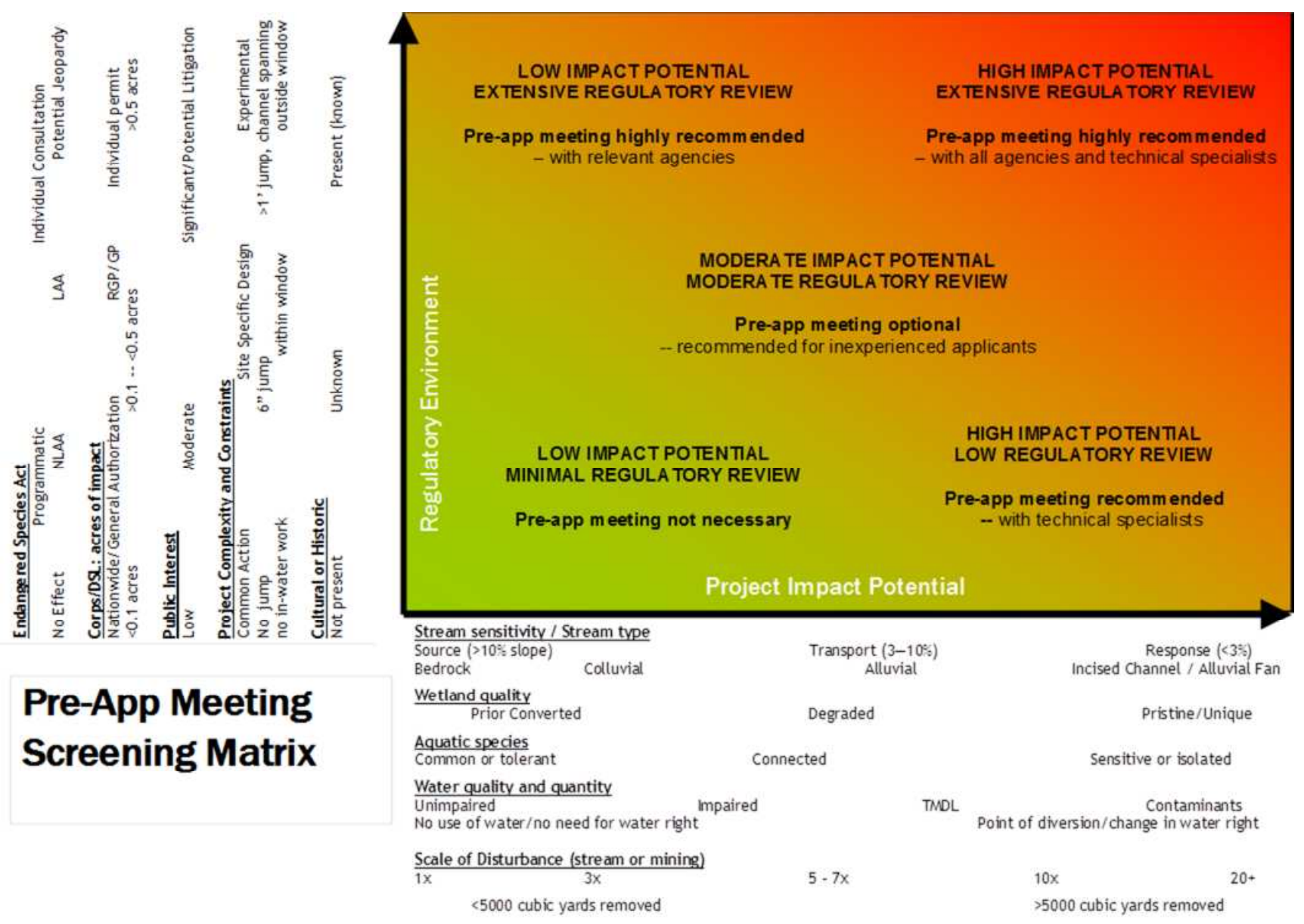

Figure 10. Pre-application screening matrix developed for use by the Oregon Department of State Lands and US Army Corps of Engineers (from USACoE (2013)). 